\title{
Erratum to: Hesperomyces virescens (Fungi, Ascomycota, Laboulbeniales) attacking Harmonia axyridis (Coleoptera, Coccinellidae) in its native range
}

Danny Haelewaters • Richard F. Comont •

Serena Y. Zhao • Donald H. Pfister

Published online: 14 March 2014

(c) Science China Press and Springer-Verlag Berlin Heidelberg 2014

Erratum to: Chin. Sci. Bull. (2014) 59(5-6):528-532

DOI 10.1007/s11434-013-0060-1

In the original publication of this paper, the first name and the last name of the first author has been documented incorrectly. The corrected information appears in this erratum.

The online version of the original article can be found under doi:10.1007/s11434-013-0060-1.

D. Haelewaters $(\bowtie)$. S. Y. Zhao · D. H. Pfister

Department of Organismic and Evolutionary Biology, Harvard University, 22 Divinity Avenue, Cambridge, MA 02138, USA

e-mail: dhaelewaters@fas.harvard.edu

\section{R. F. Comont}

NERC Centre for Ecology \& Hydrology, Maclean Building, Crowmarsh Gifford OX10 8BB, Oxfordshire, UK

\section{S. Y. Zhao}

Kraus Natural Science Building, University of Michigan,

830 North University, Ann Arbor, MI 48109, USA 